\title{
LETTERS
}

\section{Potential toxicity of topical ocular solutions}

In their 2018 CMAJ article, Kisilevsky and DeAngelis illustrated the occurrence of ocular vasculopathy in association with the administration of a topical eye decongestant. ${ }^{1}$ The pathogenesis and clinical manifestations that they reported essentially parallel the complications of use of $\alpha$-adrenergic agents in other conditions such as rhinitis medicamentosa and dermatitis medicamentosa. ${ }^{2,3}$ However, such rebound vascular effects may also be influenced by cofactors such as benzalkonium chloride, which may be present as preservatives in these pharmacologic solutions. ${ }^{4}$ Preservatives in most topical ocular products may cause direct toxicity or local allergic reactions in some patients. Either of these adverse effects could be associated subsequently with an actual or presumed vasculopathy.

Benzalkonium chloride is one of the most common and potentially toxic preservatives in topical eye solutions. ${ }^{5}$ Concentrations of this chemical vary from $0.005 \%$ to $0.02 \%$ in many targeted therapeutic ocular solutions (e.g., combined with active agents for glaucoma) or in putatively soothing or hydrating solutions more popularly referred to as "natural tears." 6 This agent can disrupt surface corneal epithelium, alter surface tear film formation and lead to surface structure necrosis. ${ }^{6,7}$ Such toxicity is dependent on dose and time accrual. ${ }^{6-8}$ In animal models, aganglionosis of the esophagus or bowel can be achieved by brief local exposures to benzalkonium chloride with similar or slightly higher concentrations $(0.02 \%$ to $0.5 \%) .{ }^{9,10}$

Other non-benzalkonium chloride, nonmedicinal constituents may also pose problems. Borate as a preservative may cause local reactions in some patients, and castor oil (used as a lipid absorption enhancer) may induce allergic reactions. ${ }^{11}$ Foreign compounds presented to the ocular surface have the potential to stimulate the induction of local allergic immunoglobulin E-mediated or type IV hypersensitivity reactions. ${ }^{12}$

Although the design of preservative-free eye solutions aims to eliminate any such direct toxicity or local allergy, most common ocular preparations continue to use antimicrobial preservatives to promote product longevity or allow for multi-use. In the interim, physicians should be wary of the potential for nonmedicinal components of ocular solutions to cause disease.

\section{Nevio Cimolai MD}

Physician, Department of Pathology and Laboratory Medicine, Faculty of Medicine, University of British Columbia, Vancouver, BC
Cite as: CMAJ 2019 August 12;191:E898. doi: $10.1503 / \mathrm{cmaj} .72457$

\section{References}

1. Kisilevsky E, DeAngelis DD. Anterior and posterior segment vasculopathy associated with long-term use of tetrahydrozoline. CMAJ 2018;190:E1208.

2. Ramey JT, Bailen E, Lockey RF. Rhinitis medicamentosa. J Investig Allergol Clin Immunol 2006;16: 148-55.

3. Werner K, Kobayashi TT. Dermatitis medicamentosa: severe rebound erythema secondary to topical bromonidine in rosacea. Dermatol Online J 2015;21. pii: 13030/qt93n0n7pp.

4. Graf P. Adverse effects of benzalkonium chloride on the nasal mucosa: allergic rhinitis and rhinitis medicamentosa. Clin Ther 1999;21:1749-55.

5. Baudouin C, Labbé A, Liang $\mathrm{H}$, et al. Preservatives in eyedrops: the good, the bad and the ugly. Prog Retin Eye Res 2010;29:312-34.

6. Noecker R. Effects of common ophthalmic preservatives on ocular health. Adv Ther 2001;18:205-15.

7. Kaur IP, Lal S, Rana C, et al. Ocular preservatives: associated risk and newer options. Cutan Ocul Toxicol 2009;28:93-103.

8. Furrer P, Mayer JM, Gurny R. Ocular tolerance of preservatives and alternatives. Eur J Pharm Biopharm 2002;53:263-80.

9. Goto S, Grosfeld JL. The effect of a neurotoxin (benzalkonium chloride) on the lower esophagus. J Surg Res 1989;47:117-9.

10. Khalil HA, Kobayashi M, Rana P, et al. Mouse model of endoscopically ablated enteric nervous system. $J$ Surg Res 2016;200:117-21.

11. Sasseville D, Desjardins M, Almutawa F. Allergic contact dermatitis caused by glycyrrhetinic acid and castor oil. Contact Dermatitis 2011;64:168-9.

12. Irkec MT, Bozkurt B. Molecular immunology of allergic conjunctivitis. Curr Opin Allergy Clin Immunol 2012; 12:534-9.

Competing interests: None declared. 